\title{
PERANAN KOMEDI KLASIK ABAD KE-17 KARYA MOLIÈRE PADA PEMERINTAHAN RAJA LOUIS XIV
}

\author{
Oleh: Alice Armini
}

\begin{abstract}
Abstrak
Komedi klasik abad ke-17 termasuk jenis sandiwara yang tujuannya selain menghibur para penoton, juga mempunyai fungsi sebagai alat untuk mengkritik masyarakat maupun pemerintah zaman itu.

Salah satu pengarang komedi abad ke-17 yang termasyhur adalah Molière. Molière selalu kritis dan berani menanggapi kenyataan kehidupan dibandingkan pengarang-pengarang drama lainnya seperti Racine dan Corneille. Di dalam karya-karyanya tercermin kebebasan pikiran dan kekayaan daya khayalnya. Melalui komedi Molière mampu melukiskan kebejatan-kebejatan dan kemunafikan golongan rohaniwan dan golongan bangsawan yang mempunyai status sosial tinggi dan hak-hak istimewa. Dalam mewujudkan kritiknya tersebut Molière menolak untuk mentaati hukum "Tiga Kesatuan", tetapi ia tetap mampu menyuguhkan suatu cerita yang menarik dan mengandung keunikan pribadi dengan mutu yang baik.

Akhirnya tidak disangkal lagi kalau Molière adalah seorang pengarang komedi yang dicintai rakyat. Molière tampil sebagai pembela kebenaran dan keadilan. Ia mempunyai sifat-sifat luhur kemanusiaan. Lewat komedinya itu, ia selalu memperjuangkan hal-hal yang tidak benar dan bertentangan dengan sifat-sifat kemanusiaan.
\end{abstract}

\section{A. Pendahuluan}

Komedi adalah sandiwara yang mengungkapkan cacat dan kelemahan sifat manusia dengan cara yang lucu, sehingga para penonton bisa lebih menghayati kenyataan kehidupan (Rendra, 1993:108).

Fungsi komedi tidak hanya untuk menyenangkan hati dan memancing gelak tawa. Komedi harus mampu membukakan mata penonton pada kenyataan kehidupan sehari-hari. Hal ini disebabkan, komedi dengan segala peristiwa yang ditampilkan langsung dapat dilihat oleh penonton.

Di dalam masyarakat Prancis abad ke-17 yang sudah maju 
peradabannya, komedi menjadi alat untuk mengkritik ketimpangan sosial dan ketidakadilan masyarakat pada waktu itu. Tulisan ini bertujuan untuk memperlihatkan/mendiskripsikan peranan komedi klasik abad ke-17 karya Molière.

\section{B.Drama Klasik di Perancis dan Konteks Sejarah Abad ke-17}

Klasisisme sebagai aliran sastra berkembang di Perancis selama abad ke-17 dan dirumuskan melalui peraturan-peraturan penulisan yang ketat. Yang berkuasa menentukan peraturan tersebut adalah Académie Française yang didirikan oleh Richelieu pada tahun 1635 dengan tujuan mengarahkan kehidupan sastra. Sastra harus menggambarkan kebenaran yang dapat diterima oleh masyarakat (Vraisemblable). Yang dituntut adalah kewajaran dan kebenaran dalam bentuk dan isi.

Drama Klasik abad ke-17 juga memiliki kaidah-kaidah yang harus dipatuhi, yang dikenal dengan les trois unités (tiga kesatuan, yaitu unité $d^{\prime}$ action (kesatuan lakuan), unité de temps (kesatuan waktu), dan unité de lieu (kesatuan tempat): cerita yang dipentaskan hanya boleh terjadi dalam satu hari, di satu tempat, dan lakuan harus sederhana, artinya terdiri dari satu alur saja dengan struktur dari paparan sampai selesaian. Selain aturan tersebut dituntut juga adanya kepatuhan akan konvensi moral, sosial dan bahasa (bienséance), yang telah disepakati masyarakat jaman itu.

Perkembangan drama klasik Perancis, sesuai dengan rejim politik dan situasi sosial budaya, dibagi menjadi tiga periode.

1. Masa pemerintahan Ratu Marie de Médicis dengan Perdana Menterinya Kardinal Richelieu, yang mewakili kekuasaan anaknya Louis XIII, yang baru berusia 9 thun ketika harus naik tahta.

2. Masa pemerintahan Perwalian berikutnya setelah kematian Louis XIII dan Richelieu pada tahun 1643, adalah pemerintahan Anne d' Autriche ibu Louis XIV, yang pada masa itu masih berusia 5 tahun, masa itu ditandai oleh meletusnya $L a$ Fronde, yakni pemberontakan kaum bangsawan dan sekelompok pemuka dalam parlemen Perancis yang ingin pula berkuasa.

3. Setelah Mazarin wafat pada tahun 1661. Masa pemerintahan Monarki Absolut oleh Louis XIV ini merupakan masa kejayaan klasisisme sebagai paham yang mengagungkan keteraturan tatanan di segala bidang.

Pada akhir masa pemerintahan raja Henri IV kondisi teater dan drama

DIKSI, Vol.7 No.18 Oktober 2000 
dianggap kurang baik, karena belum mendapat perhatian dan bantuan keuangan dari pemerintah, dan dianggap kurang pantas bagi kaum intelektual dan dipertunjukkan di hadapan Pemuka Istana. Baru pada awal pemerintahan Richelieu, kondisi drama mulai berubah dan membaik. Perhatian Richelieu pada karya seni sangat besar, dia memberi semangat dan sekaligus perlindungan pada pengarang dan pemain drama, juga mendirikan sebuah tempat pertunjukkan teater. Berkat dorongan Richelieu, banyak pengarang drama mulai mengarahkan perhatiannya pada peraturan bentuk drama.

Pada tahun 1629, para pemain drama Raja (Les Comédiens du roi) menetap di Hotel de Bourgogne. Untuk pertama kali drama menjadi genre sastra yang sangat dihargai dan mulai dipentaskan di hadapan kalangan bangsawan dan kalangan istana; jenis sastra ini mulai menghormati konvensikonvensi klasik seperti Bienséance, agar para penonton tidak merasa khawatir atau tersinggung pada waktu menyaksikan sebuah adegan drama (Scherer, 1986:426).

Setelah Richelieu wafat, kejayaan masa pemerintahan Louis XIV juga memberi dampak positif pada perkembangan drama klasik abad ke-17. Para pengarang dan pemain drama dilindungi dan diberi bantuan oleh raja.

Pengarang-pengarang drama abad ke-17 umumnya patuh pada aturanaturan klasik, seperti Racine. Tetapi, ada juga pengarang-pengarang yang sulit menerapkan aturan-aturan tersebut seperti Molière. Molière tidak suka mematuhi hukum "Tiga Kesatuan". Bentuk komedinya sangat bebas dan lancar. Ia menyuguhkan kelincahan imajinasi serta irama bercerita yang lebih beragam. Komedinya penuh improvisasi, lucu, dan tanpa ucapan muluk yang kosong. Molière banyak meminjam cerita dari sandiwara jenis "Commedia dell Arte" berasal dari Itali.

\section{Molière dan Karya-karyanya}

Molière yang nama sebenarnya Jean-Baptiste Poquelin lahir di Paris tanggal 15 Januari 1622. Dia adalah putra pertama dari Jean Poquelin, seorang penata ruangan istana raja Louis XIII. Molière menempuh pendidikan di sekolah Jésuite Collège de Clermont, sekolah terkemuka di Paris. Pada tahun 1642, dia meraih gelar dalam ilmu hukum di Université d'Orléans. Namun Molière begitu tertarik pada dunia panggung sehingga pada usia 20 tahun Molière memutuskan memilih teater sebagai lapangan kerjanya, berkat pengaruh Madeleine Béjart, tetangganya yang sangat tertarik pada dunia teater. Tahun 1643 Molière dan Madeleine mendirikan "Illustre Théâtre", dengan maksud mendirikan gedung sandiwara yang ketiga di Paris, dan ketika

Peranan Komedi Klasik Abad Ke-17..... (Alice Armini) 
itu pulalah ia mulai memakai nama Molière. Karena usaha mereka di Paris gagal, tahun 1646 pindah ke luar kota. Dan disini 12 tahun lamanya mereka berhasil mencapai cita-citanya. Tahun 1658 Molière dan rombongannya kembali ke Paris dan mengadakan pertunjukan di depan raja Louis XIV. Sejak itu mereka diberi izin bermain secara teratur di teater Kerajaan "Petit Bourbon".

Molière adalah seorang pengarang besar Perancis yang namanya dikenal di manca negara. Sudah beberapa kali karyanya dipentaskan di Eropa dengan mendapat sambutan hangat dan sudah diterjemahkan kedalam banyak bahasa. Di Indonesia namanya dikenal berkat terjemahan karya-karyanya dalam bahasa Indonesia seperti: Les Fourberies de Scapin (Akal bulus Scapin). Naskah terjemahan ini merupakan usaha penerjemahan sastra dunia yang diselenggarakan oleh Dewan Kesenian Jakarta, dan diterbitkan di tahun 1979. Beberapa lakonnya telah dipentaskan di Indonesia, seperti Si Bakhil (L'Avare) dan OKB (Le Bourgeois Gentilhomme). Memang karya-karya pengarang yang lahir 300 tahun yang lalu itu masih belum dianggap ketinggalan zaman.

Lakon-lakon Molière ditulis secara menarik dan menyenangkan, pada masa ketika pengarangnya telah mencapai kemajuan dan kematanganberpikir dan merupakan ungkapan pikiran-pikirannya tentang kehidupan manusia. Gagasan-gagasannya tetap sesuai dan aktual untuk masa kini karena menyangkut masalah-masalah universal yang berlaku sepanjang zaman, seperti masalah kesewenang-wenangan, penyalahgunaan kekuasaan, dan kemunafikan yang masih merupakan masalah aktual dan relevan dengan lingkungan abad ke-21 ini. Selain itu, lakon-lakonnya mengajarkan moral yang menganjurkan agar manusia tidak bertingkah laku melewati batas dan tetap berada dalam batas kodrat alamnya. Unsur-unsur universal dalam komedi-komedinya itulah yang menarik bagi pembaca segala zaman (Gaillard de Champris, 1960:123).

Dari tahun 1892 sampai 1941, telah diterbitkan 3316 judul yang membahas tentang kehidupan Molière, demikian juga tulisan yang menyangkut karya-karyanya banyak diterbitkan sampai saat sekarang (Ginestier P, 1975:88). Menurut statistik di La Comédie Francaise, yaitu sebuah tempat pertunjukkan teater di Paris, antara tahun 1680 sampai tahun 1967, karya-karya Molière telah dipentaskan sebanyak 28015 kali jauh lebih banyak bila dibandingkan karya-karya Corneille dan Racine keduanya yang hanya dipentaskan 15196kali (Ginestier P, 1975:89).

Walaupun telah dipisahkan oleh ratusan tahun, gagasan-gagasannya

DIKSI, Vol.7 No.18 Oktober 2000 
serta caranya menulis tetap dapat dipahami oleh pembaca masa kini. Sasaran kritiknya bersifat umum, yang bersangkutan dengan sikap dan sifat manusia yang negatif. Yang dikritik oleh Molière dalam lakonnya yang berjudul Le Bourgeois Gentilhomme misalnya adalah kalangan menengah yang meniruniru tingakah laku bangsawan agar seperti keturunan bangsawan asli, tetapi secara berlebih-lebihan, sehingga menimbulkan kesan lucu. Beberapa lakon Molière seperti lakon di atas misalnya, mempunyai kemiripan dengan apa yang masih terjadi di Indonesia, sehingga pembaca Indonesia tidak akan mendapat kesulitan untuk menangkap pesan-pesan pengarang yang tersirat di dalamnya.

Molière penulis komedi klasik abad ke-17 diakui sebagai pencipta komedi yang bermutu, sehingga kelompok teater yang dipimpinnya diizinkan mengisi pertunjukan komedi di istana pada masa pemerintahan Raja Louis XIV.

Selain menulis komedi, Molière juga menjadi sutradara dan pemain serta pemimpin grup teater. Tujuan utama Molière adalah menghibur yaitu untuk menyenangkan hati atau menciptakan suasana gembira, dan juga sekaligus mengritik kekonyolan-kekonyolan zaman itu. Molière mampu memukau sejumlah penonton karena meniru perilaku orang yang dikenal atau terkenal secara luas. Molière menggambarkan sesuatu yang dekat sekali hubungannya dengan apa yang dikenal dalam kehidupan (Voltz, 1964:74).

Molière selalu menunjukkan kritiknya pada sekelompok masyarakat tertentu. Hasilnya memang bisa pedas, tajam atau pahit dirasakan oleh orang yang merasa dikenai oleh kritik Molière. Pada umumnya Molière memasukkan unsur satire kedalam lakonnya untuk mengecam kepincangan dan ketidakadilan. Untuk itu pula ia sering mendapat peringatan karena keberaniannya mempertunjukkan kekurangan-kekurangan tertentu dalam masyarakat zamannya secara karikatural. Karyanya yang berjudul Les Précieuses Ridicules, Molière mengecam gadis-gadis desa yang meniru gaya hidup pengikut aliran La Préciosité, yaitu sekelompok wanita bangsawan yang mem punyai bahasa tersendiri dan gaya hidup mewah. Dalam Don-Juan (1655) dan Misanthrope (1966) yang dituju adalah kaum bangsawan. Sementara itu, dalam Le Bourgeois Gentilhomme (1670) yang dikritik adalah kaum menengah yang ingin berlaku seperti kaum bangsawan dab dalam $L e$ Malade Imaginaire (1669), ia mengejek sikap egois dan sok pintar para dokter. Yang disebut terakhir merupakan karyanya yang terakhir, yang ketika dipentaskan, ia sendiri berperan sebagai tokoh utamanya, yaitu si pasien. Ketika pertunjukan selesai, ia jatuh pingsan (ia memang sudah sakit-sakitan)

Peranan Komedi Klasik Abad Ke-17..... (Alice Armini) 
dan tak lama kemudian Molière meninggal dunia pada tanggal 17 Februari 1673.

\section{Komedi sebagai Alat Pendidikan Moral dan Kritik pada Masyarakat}

Dalam prakata yang disampaikan Molière kepada Louis XIV, waktu pementasan Tartuffe tahun 1669, antara lain Molière mengemukakan bahwa:

Si l'emploi de la comédie est de corriger les vices des hommes, je ne vois pas pour quelle raison il y en aura de privilégiés. Celui-ci est, dans l'Etat, d'une consequence bien plus dangereuse que les autres., et nous avons vu que le théâtre a une grande vertu pour la correction (Voltz, 1964:125).

Jika tujuan komedi untuk memperbaiki sifat jelek manusia, saya tidak melihat berdasarkan alasan apa ada hak-hak istimewa. Dalam pemerintahan hal ini berakibat lebih bahaya dibandingkan dengan hal lain, dan kita telah melihat bahwa teater mempunyai kebajikan yang besar untuk suatu perbaikan.

Di dalam prakatanya tersebut ia mengemukakan secara terbuka kritik terhadap golongan agama. Lakon Tartuffe merupakan satire sosial yang terang-terangan ditujukan untuk menyerang kaum rohaniwan yang sangat berpengaruh dalam pemerintahan Prancis pada masa itu sehingga menimbulkan reaksi yang keras dari golongan tersebut. Molière sendiri mengatakan bahwa:

La comédie a le droit de parler de tout sujet, même réligieux, sans aucun, interdit de critiquer tout groupe sosial même celui des gens d'Eglises, sans aucun privilège. (Voltz, 1964:215).

Komedi mempunyai hak untuk membicarakan segala macam pokok pemikiran termasuk tentang agama, tanpa perkecualian apapun, untuk mengkritik semua lapisan sosial, bahkan para agamawan tanpa ada hak istimewa.

Bagi Molière l:omedi tidak hanya dipakai sebagai wahana untuk menyampaikan gagasan sambil menghibur, tetapi juga dimungkinkan untuk

DIKSI, Vol.7 No.18 Oktober 2000 
menyampaikan kritik sosial yang disajikan secara karikatural.

Ancaman yang keras juga datang dari pastor Rouillé ditujukan pada Molière, karena lakonnya yang berjudul Tartuffe. Melalui pamfletnya yang berjudul "Le roi Glorieux du monde" (raja yang tersohor di dunia), mengemukakan sebagai berikut:

"Il méritait par cet attentat sacrilège et impie un dernier supplice exemplaire et public, etfeu même, avant coureur de celui de l'enfer".

Dia berhak mendapat ganjaran yang setimpal atas serangannya yang mencemarkan hal yang suci dan bersifat maksiat dengan hukuman mati juga hukuman bakar, mengawali dia masuk ke neraka.

Pamflet tersebut tidak membuat Molière mundur. Di dalam keadaan serba palsu semacam itu justru Molière tampil dengan berani. Hal itu tidak mengherankan apabila ditinjau dari awal riwayat hidupnya yang dikemukakan di muka, tampak jelas bahwa Molière pada dasarnya berasal dari golongan borjuis dan kelompok masyarakat cendekiawan. Artinya, bahwa sebagai seniman dan anggota masyarakat, ia senantiasa peka dan memperhatikan apa yang terjadi di sekelilingnya. Melalui pengamatannya terhadap kehidupan masyarakatnya, Molière menemukan berbagai hal, baik yang menggembirakan maupun yang memprihatinkan.

Situasi kehidupan golongan agama pada abad ke-17 menyebabkan keprihatinannya dan telah menggugah perasaan serta merangsang ketajaman kritiknya yang disalurkannya melalui komedi. Baginya komedi dapat mengungkapkan cacat dan kelemahan sifat manusia dengan cara yang lucu, sehingga para penonton dengan mudah, tanpa berpikir, memahami kehidupan sehari-hari. Di dalam masyarakat yang kehidupannya sudah lebih maju, komedi merupakan ajang pertunjukan untuk menertawakan cacat kelemahan masyarakat sendiri, sehingga isi komedi mereka bersifat kritis dan cerdas (Rendra, 1993:108). Melalui lakonnya Tartuffe yang berbentuk komedi, Molière berusaha mengungkapkan cacat golongan agama abad ke-17 dan masyarakat yang fanatik.

Banyak terjadi kemunafikan terhadap norma-norma agama dalam masyarakat Prancis abad ke-17, terutama oleh kaum agama sendiri. Molière ingin memberi informasi atau pesan bahwa hendaknya masyarakat jangan hanya melihat penampilan seseorang dalam bidang apapun juga dalam

Peranan Komedi Klasik Abad Ke-17..... (Alice Armini) 
bidang agama, tetapi seharusnya seseorang dinilai melalui tindakan dan sepak terjangnya, bukan dari kata-katanya saja. Persoalan kemunafikan yang terdapat dalam lakon Tartuffe merupakan potret kemunafikan golongan agama abad ke-17. Molière ingin lebih terang-terangan membidik sasaran kritiknya dan menyerang keras khususnya pranata katolik tetapi ia juga mengkritik para penganut agama, yaitu penganut saleh yang beribadah dengan taat, namun melupakan hakekat agama, yaitu memelihara kebahagiaan dan kesejahteraan manusia. Komedi ini merupakan ajaran hidup, tetapi sekaligus merupakan ejekan terhadap kenyataan sosial yang ada di sekitarnya.

\section{E. Komedi Klasik dan Kekuasaan Raja Louis XIV}

Masyarakat Prancis pada waktu itu terdiri dari golongan agama, bangsawan, dan Tiers-état (golongan borjuis, pengrajin dan kaum tani), struktur pemerintahan di Prancis pada masa Louis XIV masih berpedoman pada pemerintahan kerajaan, yang berpusat di Istana Versailles, 16 kilometer dari kota Paris. Dalam kerajaan pimpinan tertinggi adalah raja. Raja muda Louis XIV memerintah negaranya sebagai raja du Droit-divin (doktrin abad ke-17 yang mengatakan bahwa raja adalah utusan Tuhan) dengan kekuasaan mutlak, sehingga timbul adanya pemerintahan monarki absolut. Keputusan Louis XIV mengangkat dirinya sebagai raja utusan Tuhan dilatar belakangi oleh situasi politik masa itu. Bayangan yang menakutkan mengenai pemberontakan La Fronde tidak pernah dilupakan oleh raja. La Fronde yakni pemberontakan kaum bangsawan dan sekelompok pemuka dalam parlemen, berlangsung selama empat tahun dari tahun 1648 sampai tahun 1652, ketika usia raja masih di bawah umur. Gerakan tersebut bertujuan melawan para penguasa raja, karena adanya beban pajak yang tinggi untuk membiayai perang (Universalis, corpus 9, 1990:970).

Louis XIV menarik pelajaran dari situasi tersebut, kematian perdana menteri Mazarin pada tahun 1661, memungkinkan raja untuk memerintah kerajaan. Kekuasaan raja sangat besar dalam masyarakat, hubungan raja dengan rakyat diatur melalui birokrasi yang ketat. Raja bertindak menurut keyakinan pribadinya, semua keputusan berada di tangan raja. Dia juga yang mengambil keputusan untuk tidak mengangkat seorang perdana menteri, mengendalikan semua anggota parlemen, menjauhkan kaum bangsawan dari urusan politik, dan dia sendiri secara langsung mengatur segala urusan kerajaan dan mengharuskan kepada semua orang untuk mentaati peraturanperaturan yang dibuatnya.

Orang-orang yang dipercaya raja Louis XIV membantu

DIKSI, Vol.7 No.18 Oktober 2000 
pemerintahannya kebanyakan diambil dari golongan borjuis. Adapun nama yang menempati dewan hakim tinggi adlaah keluarga Mole, keluarga Segnier, keluarga Pomponne, sedangkan jabatan administrasi tinggi negara adalah Colbert dengan putranya Segnelay, Le Tellier dan putranya Louvais, juga dalam bidang filsafat seperti Descarte, Arnauld, Perrault, Pascal, Fontenele, dan di bidang sastra, Chapelain, Boileau, Corneille, Racine dan Molière, semuanya datang atau berasal dari kalangan Borjuis. Selanjutnya dengan gaji yang diterimanya dari raja, orang-orang ini dapat membeli gelar kebangsawanan (Noblesse-de-robe) dan hidup dengan gaya bangsawan pula. Hanya ada dua nama yang berasal dari golongan bangsawan yang membantu raja, yaitu Rochefoucauld dan Fenelon, dan seorang dari golongan agama yaitu Bossuet. Peran para bangsawan pada masa pemerintahan Louis XIV hanya dalam bidang kemiliteran seperti Conde dan Turenne, atau peran mereka hanya menghiasi istana (Universalis, corpus 4, 1990: 441). Dengan maksud terselubung agar kaum bangsawan tidak mampu lagi menyusun kekuatan di daerah, Louis XIV mendatangkan dan menempatkan mereka di istana Versailles, dengan menawarkan segala kesenangan. Tujuan Louis XIV tidak lain hanya ingin melumpuhkan kekuasaan mereka.

Dalam bidang kebudayaan, istana raja dapat dikatakan sebagai pusat kebudayaan, karena segala aktivitas kesenian seperti: seni tari, seni musik, dan seni sastra, timbul di kalangan istana. Louis XIV sering mengadakan pesta-pesta dan pertunjukkan kesenian di istana guna menghibur para penghuni istana Versailles. Masa pemerintahan Louis XIV juga merupakan masa kejayaan klasisisme sebagai paham yang mengagungkan keteraturan tatanan di segala bidang. Kerajaan menjadi pusat orientasi berbagai kehidupan masyarakat. Louis XIV tidak hanya mengendalikan pemerintahannya tetapi juga di bidang seni. Adanya latar belakang tentang aturan klasisisme, jelaslah bahwa pengarang abad ke-17 tidak dapat berkreasi dengan sebebas-bebasnya. Mereka terikat pada aturan-aturan yang telah ditentukan. Karya mereka yang tidak sesuai dengan aturan-aturan itu akan ditolak atau setidaknya mengalami sensor, seperti yang terjadi pada kasus lakon Tartuffe versi pertama pada tahun 1664. Walaupun demikian, lakon Tartuffe versi pertama yang dipentaskan tahun 1669 mengalami sukses besar. Kritik yang tercantum dalam Tartuffe jelas amat tajam terhadap golongan agama yang dikategorikan sebagai golongan yang menempati lapisan sosial terting gi pada abad ke-17, meskipun demikian lakon Tartuffe ternyata mampu meloloskan diri dari sensor.

Kelolosan Tartuffe dari sensor itu bukanlah faktor kebetulan melainkan

Peranan Komedi Klasik Abad Ke-17..... (Alice Armini) 
karena komposisi drama tersebut telah ditata sedemikian rupa sehingga sekaligus merupakan kekhasan lakon Tartuffe dalam hal bentuk yaitu Molière tidak mengindahkan lagi apa yang dinamakan kesatuan laku, sehingga jalan ceritanya lebih dari satu. Dalam hal komposisi Molière tampak bersifat hatihati dalam menampilkan cerita yang berisi kritik terhadap golongan agama. Kunci keberhasilan Tartuffe selain terletak pada faktor-faktor yang dikemukakan di atas, faktor yang lebih penting yang dikemukakan oleh Benichou dalam bukunya Morales du Grande siecle (1948:344) yaitu: Louis XIV melindungi Molière dari musuh-musuhnya yang datang dari kalangan agamawan. Hal itu disebabkan para rohaniwan tidak senang pada raja atau karena mereka terlalu mengawasi urusan percintaan raja. Disamping itu, situasi kerajaan pada waktu itu sedang dalam masa kejayaan dan penuh kegembiraan, sehingga mempunyai rasa toleransi yang besar terhadap beberapa perkembangan kemajuan kehidupan, terutama datang dari kalangan atas.

\section{F.Penutup}

Dari uraian yang telah dilakukan, dapat ditarik kesimpulan bahwa tidak berlebihan kiranya kalau kehadiran komedi klasik, seperti lakon Tartuffe cukup berarti bila dikaitkan dengan temanya yang universal sifatnya, yang isinya mengajarkan moral. Karya Molière banyak mengandung kritik keadaan abad ke-17 namun masih mencerminkan kebenaran untuk masa sekarang. Kemunafikan dan kezaliman selalu ada sepanjang masa.

Akhirnya tidak mengherankan kalau nama Molière selalu harum pada zamannya dan di dalam sejarah. Sampai kini karyanya masih dimainkan dengan sambutan yang selalu meriah di dunia ini.

\section{DAFTAR PUSTAKA}

Benac, Henri.(1969). Le Classicisme. Paris: Hachette.

Bénichou, Paul. (1948). Morales du Grand siècle. Paris: Gallimard.

Caput, JP. (1971). Molière, Tartuffe. Paris: Librairie Larousse.

Corvin, Michel.(1985). Molière et ses metteurs en scène d'aujourd' hui. Paris: Presses universitaire de lyon.

DIKSI, Vol.7 No.18 Oktober 2000 
Ferreyrolles, Gerard.(1987). Molière, Etudes litteraires. Presses universitaires de France.

Gaillar, Henri. (1960). Les Ecrivains classique. Paris: Edition mondial, Del, Ducal.

Ginestier, P. 1975. Valeurs actuelles du théâtre classique. Bordas etude 38.

Loroy. L, Emmanuel. (1991). L'Aucien Régime de Louis XIII Louis XV 16101770, Histoire de France. Paris: Hackette.

Rendra. (1993). Seni drama untuk remaja. Jakarta: PT. Dunia Pustaka.

Sherer, Jacques. (1980). La Dramaturgie classique en France. Paris: Nizet. Voltz, Pierre. (1964). La Comédie. Collection U. Paris: Armand Colin. 